\section{Prognostic False-Positivity and Cost-Effectiveness in Sentinel Node Biopsy in Melanoma}

\section{TO THE EDITORS:}

The calculations made by Morton et al. ${ }^{1}$ about the costeffectiveness of sentinel node biopsy (SNB), published in a recent issue of this Journal, depend entirely on the accuracy of the claimed $20 \%$ survival difference between two groups of patients having immediate (122/764) versus delayed lymphadenectomy $(78 / 500)$ as reported in the third interim analysis of MSLT $-1^{2}(72.3 \pm 4.6 \%$ versus $52.4 \pm$ $5.9 \%)$.

This raises two concerns: first, that the survival difference is derived from a comparison of two postrandomization, selected subgroups of patients and is therefore subject to bias and other inaccuracies, and second, that the authors of MSLT-1 assume without proof that all positive sentinel nodes $(\mathrm{SN})$ if not removed will inevitably progress to palpable nodal recurrence.

Morton et al. have failed to include the 26 false-negative patients in the biopsy arm who progressed to palpable nodal recurrence and had delayed lymphadenectomy. These patients were probably SN-positive but this was not identified by the SNB procedure. Therefore, 15.6\% (78/ 500) of patients developed nodal recurrence as site of first recurrence in the observation arm versus $19.4 \%$ ([122+ 26]/764) in the biopsy arm. In the absence of any difference in overall survival from the point of randomization in MSLT-1, one would expect the incidence of nodal recurrence in both arms of the trial to be similar. Therefore, it is likely that a proportion of the 122 patients who were SNpositive were prognostically false-positive. ${ }^{3}$ Other authors have suggested that some tiny deposits of melanoma in the sentinel node have no adverse prognostic significance and should be considered negative. ${ }^{4}$

Currently, the protagonists of the SNB procedure are reluctant to consider the possibility of prognostic falsepositivity. However, in a recent article from the same unit and by the same senior author the following sentence appears: "Based on the evidence that is available at present, it is not clear whether all melanoma metastases, including very small tumour deposits within the subcapsular sinus of the SNs, are clinically relevant." 5 That statement is likely to be correct because a $20 \%$ survival advantage in a subgroup of this magnitude would almost certainly reflect at least as a trend toward an overall survival advantage from the point of randomization, which we know not to be the case.

\section{J. Meirion Thomas}

Surgical Oncology, Royal Marsden Hospital, London, UK e-mail: meirion@ roseway.demon.co.uk

Published Online: 1 July 2009

(C) Society of Surgical Oncology 2009

\section{REFERENCES}

1. Morton RL, Howard K, Thompson JF. The cost-effectiveness of sentinel node biopsy in patients with intermediate thickness primary cutaneous melanoma. Ann Surg Oncol. 2009;16:929-40.

2. Morton DL, Thompson JF, Cochran AJ, et al. Sentinel-node biopsy or nodal observation in melanoma. N Engl J Med. 2006;355:130717.

3. Thomas JM. Prognostic false-positivity of the sentinel node in melanoma. Nat Clin Pract Oncol. 2008;5:18-23.

4. van Akkooi AC, Bouwhuis MG, van Geel AN, et al. Clinical relevance of melanoma micrometastases $(<0.1 \mathrm{~mm})$ in sentinel nodes: are these nodes to be considered negative? Ann Oncol. 2006;17:1578-85.

5. Scolyer RA, Rajmohan M, Satzger I, et al. The detection and significance of micrometastases in sentinel nodes. Surg Oncol. 2008; 17:165-74. 